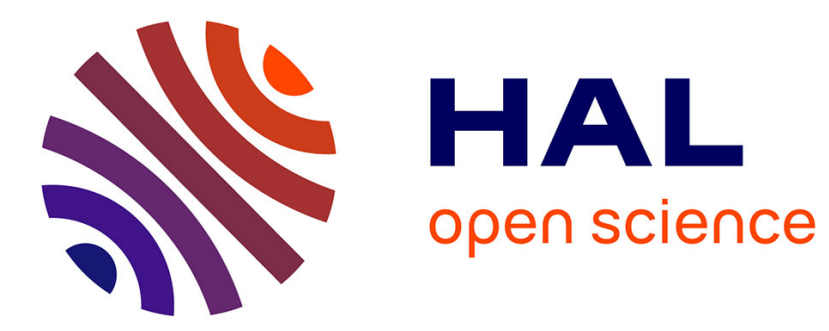

\title{
INVESTIGATION OF MIXED INTERMETALLIC COMPOUNDS
}

\author{
I. Vincze, M. Cadeville, R. Jesser, L. Takács
}

\section{To cite this version:}

I. Vincze, M. Cadeville, R. Jesser, L. Takács. INVESTIGATION OF MIXED INTERMETALLIC COMPOUNDS. Journal de Physique Colloques, 1974, 35 (C6), pp.C6-533-C6-536. 10.1051/jphyscol:19746113 . jpa-00215725

\section{HAL Id: jpa-00215725 https://hal.science/jpa-00215725}

Submitted on 1 Jan 1974

HAL is a multi-disciplinary open access archive for the deposit and dissemination of scientific research documents, whether they are published or not. The documents may come from teaching and research institutions in France or abroad, or from public or private research centers.
L'archive ouverte pluridisciplinaire HAL, est destinée au dépôt et à la diffusion de documents scientifiques de niveau recherche, publiés ou non, émanant des établissements d'enseignement et de recherche français ou étrangers, des laboratoires publics ou privés. 


\title{
INVESTIGATION OF MIXED INTERMETALLIC COMPOUNDS
}

\author{
I. VINCZE $(*)$, M. C. CADEVILLE $\left({ }^{* *}\right)$, R. JESSER $(* * *)$, L. TAKÁCS $(*)$
}

\begin{abstract}
Résumé. - On présente les résultats des mesures d'effet Mössbauer sur les composés intermétalliques $\left(\mathrm{Fe}_{1-x} \mathrm{Co}_{x}\right){ }_{2} \mathrm{~B}(0 \leqslant x<1),\left(\mathrm{Fe}_{1-x} \mathrm{Co}_{x}\right) \mathrm{B}(0 \leqslant x \leqslant 0,5)$ et $\left(\mathrm{Fe}_{1-x} \mathrm{Mn}_{x}\right) \mathrm{Be}_{2}(0 \leqslant x<1)$. La densité électronique (c'est-à-dire le déplacement isomérique) aux sites du fer n'est pas changée par alliage dans chacun de ces systèmes. Les valeurs du champ hyperfin suggèrent un moment du fer pratiquement constant dans $\left(\mathrm{Fe}_{1-x} \mathrm{Co}_{x}\right)_{2} \mathrm{~B}$ et $\left(\mathrm{Fe}_{1-x} \mathrm{Co}\right) \mathrm{B}$ alors qu'il diminue dans $\left(\mathrm{Fe}_{1-x} \mathrm{Mn}_{x}\right) \mathrm{Be}_{2}$. La comparaison avec l'aimantation moyenne pour $\left(\mathrm{Fe}_{1-x} \mathrm{Co} x\right)_{2} \mathrm{~B}$ et $\left(\mathrm{Fe}_{1-x} \mathrm{Mn}_{x}\right) \mathrm{Be}_{2}$ suggère une diminution importante des moments magnétiques des atomes de Co et Mn respectivement.
\end{abstract}

\begin{abstract}
The results of Mössbauer measurements on the intermetallic compounds $\left(\mathrm{Fe}_{1-x} \mathrm{Co}_{x}\right)_{2} \mathrm{~B}(0 \leqslant x<1),\left(\mathrm{Fe}_{1-x} \mathrm{Co} x\right) \mathrm{B}(0 \leqslant x \leqslant 0.5)$ and $\left(\mathrm{Fe}_{1-x} \mathrm{Mn}_{x}\right) \mathrm{Be}_{2}(0 \leqslant x<1)$ are presented. The electron density (i. e. the isomer shift) at the iron sites remains unchanged for alloying in each of these systems. The hyperfine field values suggest a nearly constant iron moment in $\left(\mathrm{Fe}_{1-x} \mathrm{Co}_{x}\right)_{2} \mathrm{~B}$ and $\left(\mathrm{Fe}_{1-x} \mathrm{Co}_{x}\right) \mathrm{B}$, whereas it decreases in $\left(\mathrm{Fe}_{1-x} \mathrm{Mn}_{x}\right) \mathrm{Be}_{2}$. The comparison with the average magnetization for the $\left(\mathrm{Fe}_{1-x} \mathrm{Co}_{x}\right)_{2} \mathrm{~B}$ and $\left(\mathrm{Fe}_{1-x} \mathrm{Mn}_{x}\right) \mathrm{Be}_{2}$ compounds suggests an important decrease in the magnetic moments of $\mathrm{Co}$ and $\mathrm{Mn}$ atoms, respectively.
\end{abstract}

The considerable similarity in the magnetic moment versus electron concentration curve of the isomorph series of $T_{2} B$ and $T B$ compounds $(T=3 d$ transition element) to the Slater-Pauling curve of the same transition-metal alloys led to the assumption [1] that the valence electrons of the metalloid transfer to the d-band of the metals (the so-called donor model). This electron transfer causes a shift of the Slater-Pauling curve as a whole to the lower electron concentration by about 1.5 electrons for each added boron atom. The low temperature specific heat measurements [2] supported this idea and the model was extended [3] for ternary alloys formed from $\mathrm{FeBe}_{2}$ by substitution of other $3 \mathrm{~d}$ metals.

There is a correlation in these binary compounds between the magnetic moment and isomer shift at iron sites in agreement with the expectation that the metalloid fills the d-band of the metal (Fig. 1). The increase in the isomer shift corresponds either to a decrease in the $4 \mathrm{~s}$ - or to and increase in the $3 \mathrm{~d}$-electron density. The main contribution to the iron hyperfine field for these compounds is the core polarization contribution (i. e. proportional to their own magnetic moment), thus the latter case is preferred,i. e. the iron 4 s-electron density at the Fermi surface is thought to be very small [7]. These experimental data support the

(*) Central Research Institute for Physics, H-1525 Budapest, POB 49, Hungary.

(**) Université Louis-Pasteur, Laboratoire de Structure Electronique des Solides, 67-Strasbourg, France.

(***) Université Louis-Pasteur, Laboratoire Pierre-Weiss, 67084 Strasbourg, France. view that the extra electrons of the metalloid enter the spin-down d-band of iron and that one extra electron results in about $0.2 \mathrm{~mm} / \mathrm{s}$ increase in the isomer shift and about $130 \mathrm{kOe}$ decrease in the hyperfine field. Although it is realized that the fit in figure 1 is not outstanding, it should be emphasized that the crystal structure and thus the overlap contributions in these compounds are rather different.

The next step in the investigation of the charge transfer mechanism is the study of pseudobinary systems containing the mixture of two metal atoms. The magnetic properties of such compounds are often explained in terms of a rigid band model : the metal d-electrons fill the common d-band. Little or no information is known for the electron and magnetic moment distribution at the individual metal atom sites. In dilute iron-based alloys the charge screening of the 3d-impurities in the common $3 \mathrm{~d}$-band results in a considerable perturbation of the charge and spin density (i. e. isomer shift and hyperfine field) at the iron sites [8].

Our aim is to compare the charge screening mechanism found in a typical metal (iron) with that in typical pseudobinary intermetallic compounds. For this comparison the following systems were selected: $\left(\mathrm{Fe}_{1-x} \mathrm{Co}_{x}\right)_{2} \mathrm{~B}(0 \leqslant x<1),\left(\mathrm{Fe}_{1-x} \mathrm{Co}_{x}\right) \mathrm{B}(0 \leqslant x \leqslant 0.5)$, and $\left(\mathrm{Fe}_{1-x} \mathrm{Mn}_{x}\right) \mathrm{Be}_{2}(0 \leqslant x<1)$. The hyperfine field, the isomer shift and the quadrupole splitting were measured by Mössbauer effect as a function of composition and temperature between $80 \mathrm{~K}$ and $1100 \mathrm{~K}$. The spectra were recorded in a 1024 channel analyser with a conventional constant-acceleration Mössbauer spectrometer using a $20 \mathrm{mCi}{ }^{57} \mathrm{Co}$ in chromium source. 


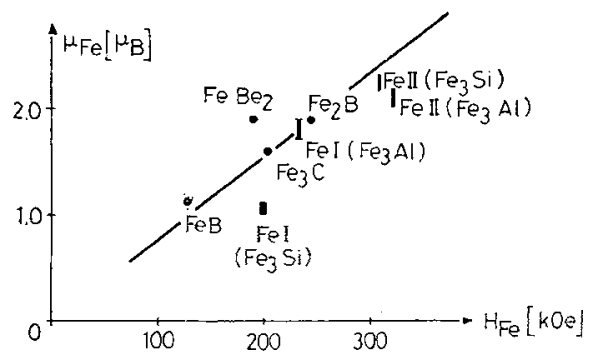

$a_{1}$
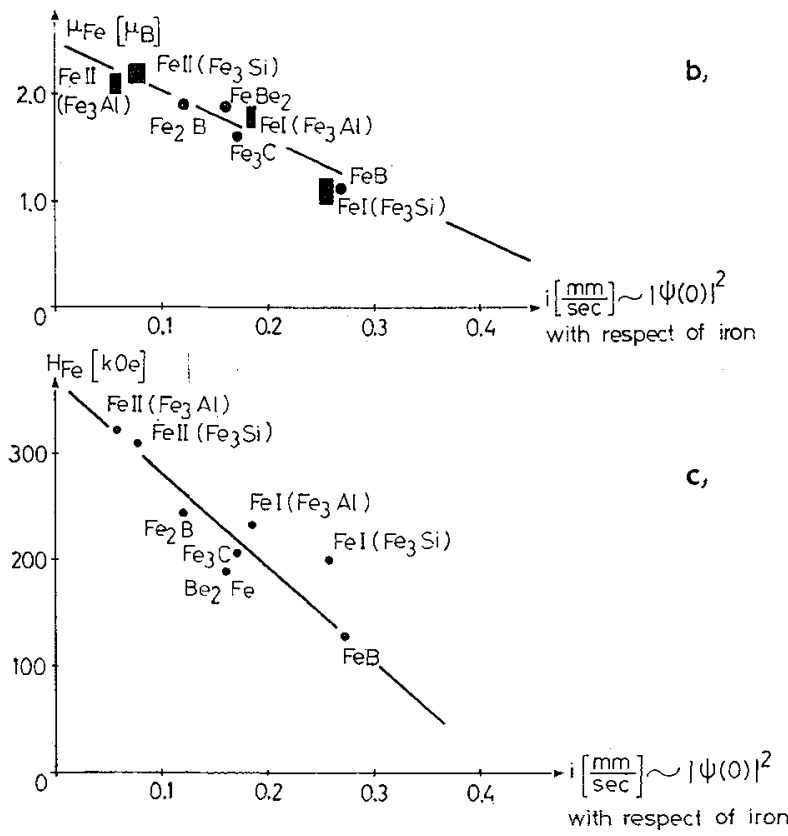

FIG. 1. - Correlations between the iron magnetic moment, hyperfine field and isomer shift. The iron moment values are taken from magnetization $[1,4]$ and neutron [5] measurements, the hyperfine field and isomer shift values are our own data (except for $\mathrm{Fe}_{3} \mathrm{C}[6]$ ).

The deviations from linearity of the velocity sweep were less than $0.1 \%$.

The samples were prepared from $99.8 \%$ pure boron, $99.5 \%$ pure beryllium and $99.9 \%$ pure transition metals by induction melting under pure argon and homogenized by vacuum annealing. The samples showed the correct crystalline structure when examined by X-ray diffraction. For the Mössbauer measurements powder samples (grain size less than $50 \mu \mathrm{m}$ ) were used. All these samples form a solid solution with a crystal structure based on the structure of $\mathrm{Fe}_{2} \mathrm{~B}, \mathrm{FeB}$, and $\mathrm{FeBe}_{2}$, respectively. These crystal structures, where the iron sites are crystallographically equivalent, are the following [9] :

$\mathrm{Fe}_{2} \mathrm{~B}$ : body-centred-tetragonal $\left(\mathrm{CuAl}_{2}\right.$-type $)$ $\mathrm{C}-16$ structure; a typical iron atom has 11 nearest iron neighbours, the distances ranging from $2.40 \AA$ to $2.72 \AA$.

$\mathrm{FeB}$ : orthorhombic B 27-type crystal structure; the distances of the 10 nearest iron neighbours of an iron atoms ranging from $2.6 \AA$ to $2.9 \AA$.
$\mathrm{FeBe}_{2}$ : hexagonal $\left(\mathrm{MgZn}_{2}\right.$-type) $\mathrm{C}-14$ structure ; an iron has 4 iron first neighbours at $2.56 \AA$.

The Mössbauer spectra of $\left(\mathrm{Fe}_{1-x} \mathrm{Co}_{x}\right)_{2} \mathrm{~B}$ and $\left(\mathrm{Fe}_{1-x} \mathrm{Co}_{x}\right) \mathrm{B}$ are very similar to a broadened spectra of the pure $\mathrm{Fe}_{2} \mathrm{~B}$ and $\mathrm{FeB}$, no resolvable satellites were observed. Thus the fit of a single six-line pattern to the spectra gave a reasonable good description and determined the values of the average isomer shift and hyperfine field. On the other hand, in the case of $\left(\mathrm{Fe}_{1-x} \mathrm{Mn}_{x}\right) \mathrm{Be}_{2}$ we could resolve the six-line patterns corresponding to the iron atoms with different number of Mn first neighbours (i. e. with 0 , 1, etc. $n n \mathrm{Mn}$ ). In the following a short summary of the main experimental results is presented.

Figure 2 shows the values of the average isomer shift in the $\left(\mathrm{Fe}_{1-x} \mathrm{Co}_{x}\right)_{2} \mathrm{~B}$ and $\left(\mathrm{Fe}_{1-x} \mathrm{Mn}_{x}\right) \mathrm{Be}_{2}$ systems.
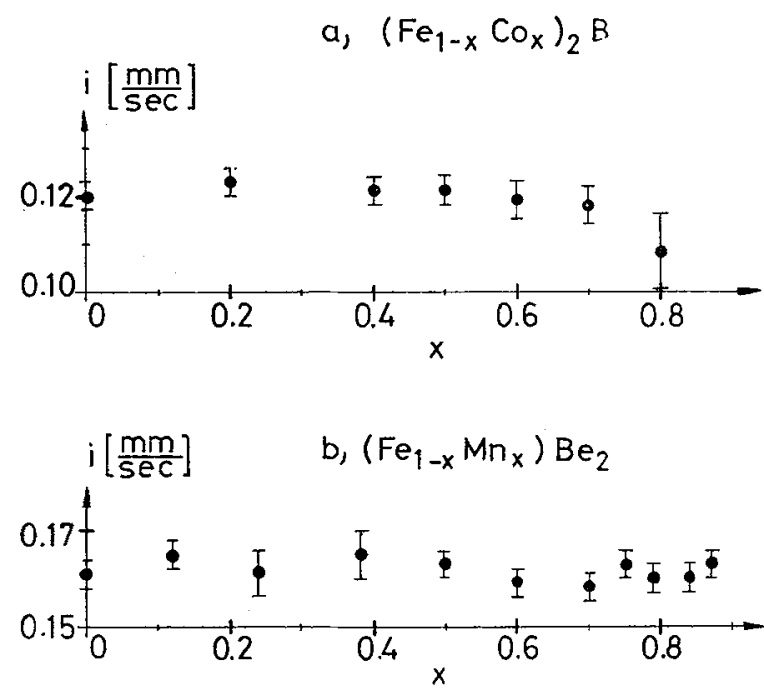

FIG. 2. - Room temperature values of the average isomer shift of iron in $\left(\mathrm{Fe}_{1-x} \mathrm{Co}_{x}\right)_{2} \mathrm{~B}$ and $\left(\mathrm{Fe}_{1-x} \mathrm{Mn}_{x}\right) \mathrm{Be}_{2}$ (relative to pure iron).

Within the experimental error (about $\pm 0.003 \mathrm{~mm} / \mathrm{s}$ ) these values are independent of the concentration of the substituted elements. Exactly the same behaviour was found for $\left(\mathrm{Fe}_{1-x} \mathrm{Co}_{x}\right) \mathrm{B}$ (the value of the isomer shift is $0.263(3) \mathrm{mm} / \mathrm{s}$ (relative to iron)), and moreover, in $\left(\mathrm{Fe}_{1-x} \mathrm{Mn}_{x}\right) \mathrm{Be}_{2}$ the isomer shift values were the same for the individual iron atoms with different $\mathrm{Mn}$ neighbourhood.

The average iron hyperfine field decrease slowly at $\mathrm{Co}$ substitution in $\left(\mathrm{Fe}_{1-x} \mathrm{Co}_{x}\right) \mathrm{B}: \mathrm{d} \mathbf{H} / \mathrm{d} c=(-8 \pm 5) \mathrm{kOe}$ at $80 \mathrm{~K}$. In this system the average magnetization decreases essentially according to the simple dilution [1]. In agreement with this, the iron moment remains unchanged (and $\mu_{\mathrm{Co}} \approx 0$ ), which is reflected in the nearly constant iron hyperfine field. The small decrease in the hyperfine field can be attributed to the change in the transfer contribution of the nearest neighbours. 
The situation is very similar in $\left(\mathrm{Fe}_{1-x} \mathrm{Co}_{x}\right)_{2} \mathrm{~B}$ that is shown in figure $3 a$. The average iron hyperfine field slowly decreases again for Co substitution, the total change is $\mathrm{dH} / \mathrm{d} c=(-23.9 \pm 0.6) \mathrm{kOe}$. This decrease in the iron hyperfine field could correspond a similar decrease (totally about $0.2 \mu_{\mathrm{B}}$ ) in the average iron magnetic moment for increasing Co concentration. It is more probable, however, that the dominant part of the decrease originates from the decrease in the transfer contributions to the hyperfine field. This is expected to be somewhat larger than in $\left(\mathrm{Fe}_{1-x} \mathrm{Co}_{x}\right) \mathrm{B}$ due to the smaller number of $B$ neighbours which screen the iron less effectively and to the shorther distance of the transition metal neighbours. The average magnetization per transition metal atom curve of $\left(\mathrm{Fe}_{1-x} \mathrm{Co}_{x}\right)_{2} \mathrm{~B}$ indicates [10] an increase above the simple dilution line. This deviation could be explained by the assumption that the average Co magnetic moment linearly decreases for increasing Co concentration. If the iron moment is constant in the whole concentration range, $\mu_{\mathrm{Co}}$ decreases from $1.25 \mu_{\mathrm{B}}$ at $x=0$ to $0.80 \mu_{\mathrm{B}}$ at $x=1$. Preliminary NMR investigation of ${ }^{69} \mathrm{Co}$ confirms this assumption.
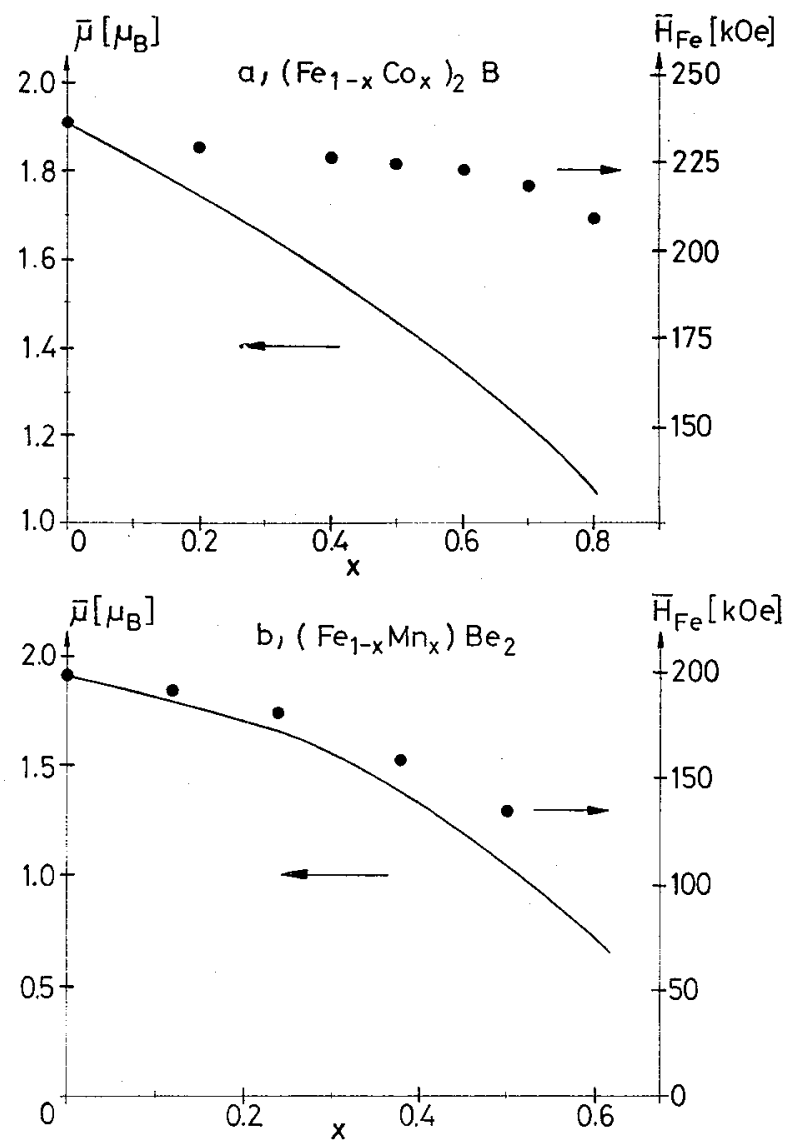

FIG. 3. - Average hyperfine field at iron (black points) : a) at room temperature in $\left(\mathrm{Fe}_{1-x} \mathrm{Co}_{x}\right)_{2} \mathrm{~B}$ and $\left.b\right)$ at $80 \mathrm{~K}$ in $\left(\mathrm{Fe}_{1-x} \mathrm{Mn}_{x}\right) \mathrm{Be}_{2}$. The figure contains the low temperature average magnetization per transition metal atom (full line) a) for $\left(\mathrm{Fe}_{1-x} \mathrm{Co}_{x}\right)_{2} \mathrm{~B}$ measured by Cadeville [10] and $\left.b\right)$ for $\left(\mathrm{Fe}_{1-x} \mathrm{Mn}_{i}\right) \mathrm{Be}_{2}$ measured by Jesser et al. [11].
The magnetic behaviour of $\left(\mathrm{Fe}_{1-x} \mathrm{Mn}_{x}\right) \mathrm{Be}_{2}$ is rather different from the previous two systems figure $3 b$. The average magnetization per transition metal atom curve shows [11] a breakdown above $x=0.24$ which leads to the disappearance of the ferromagnetism around $x=0.75$. The average iron hyperfine field calculated from the hyperfine field distribution follows quite well the course of the average magnetization. For this system the transfer hyperfine field contribution is expected to be smaller than in $\left(\mathrm{Fe}_{1-x} \mathrm{Co}_{x}\right)_{2} \mathrm{~B}$ and $\left(\mathrm{Fe}_{1-x} \mathrm{Co}_{x}\right) \mathrm{B}$, since the $\mathrm{Fe}$ atoms are surrounded by $12 \mathrm{Be}$ atoms (whereas there are 4 and $6 \mathrm{~B}$ neighbours in $\mathrm{Fe}_{2} \mathrm{~B}$ and $\mathrm{FeB}$, respectively), resulting in a larger isolation of the $\mathrm{Fe}$ atoms from their transition metal neighbourhood. Assuming (without any strict evidence) that the average iron hyperfine field is proportional to the average iron moment, a twice larger decreases is expected in the average $\mathrm{Mn}$ moment than in the average moment of $\mathrm{Fe}: \mathrm{i}$. e. $\bar{\mu}_{\mathrm{Be}}$ decreases from $1.9 \mu_{\mathrm{B}}$ at $r=0$ to $1.3 \mu_{\mathrm{B}}$ at $x=0.5$ whereas $\bar{\mu}_{\mathrm{Mn}}$, decreases from $1.9 \mu_{\mathrm{B}}$ at $x=0$ to $0.6 \mu_{\mathrm{B}}$ at $x=0.5$. The magnetic moment of iron atoms seems to be well determined by their first neighbourhood. For example, the hyperfine field at iron atoms without $\mathrm{Mn}$ first neighbours is the same as in pure $\mathrm{FeBe}_{2}$ independently of the Mn concentration. The addition of $\mathrm{Mn}$ into the first coordination shell reduces this hyperfine field, e. g. a single first neighbour $\mathrm{Mn}$ causes a $(17.0 \pm 0.5) \mathrm{kOe}$ decrease independently of the $\mathrm{Mn}$ concentration at least up to $x=0.5$. If the hyperfine field is unambiguously determined by the magnetism of the atom itself, then the moment of Fe with full Mn first neighbourhood is about $1.0 \mu_{\mathrm{B}}$.

The temperature dependence of the relative hyperfine field (normalized to the value taken at $80 \mathrm{~K}$ ) as a function of the reduced temperature (normalized to the Curie temperature) is about the same for each of the investigated systems, i. e. the magnetization is independent of the local neighbourhood.

In conclusion, these results seem to support the view that in these compounds the electron density at the iron sites is unchanged for alloying - a behaviour which is rather different from the behaviour of the similar binary alloys. The magnetic moment of iron atoms was found to be nearly constant in $\left(\mathrm{Fe}_{1-x} \mathrm{Co}_{x}\right)_{2} \mathrm{~B}$ and $\left(\mathrm{Fe}_{1-x} \mathrm{Co}_{x}\right) \mathrm{B}$, whereas it decreases in $\left(\mathrm{Fe}_{1-x} \mathrm{Mn}_{x}\right) \mathrm{Be}_{2}$. The comparison of the average iron hyperfine field with the average magnetization for the $\left(\mathrm{Fe}_{1-x} \mathrm{Co}_{x}\right)_{2} \mathrm{~B}$ and $\left(\mathrm{Fe}_{1-x} \mathrm{Mn}_{x}\right) \mathrm{Be}_{2}$ compounds suggests an important decrease in the magnetic moments of $\mathrm{Co}$ and $\mathrm{Mn}$ atoms, respectively - in good agreement with recent ${ }^{59} \mathrm{Co}$ NMR measurements on the former system. The previously mentioned constant isomer shift suggests that the mechanism of the iron moment decrease in $\left(\mathrm{Fe}_{1-x} \mathrm{Mn}_{x}\right) \mathrm{Be}_{2}$ is not a simple donation of extra electrons into the iron $3 \mathrm{~d}$ spin-down band, but a decrease in the magnetic splitting of the $3 \mathrm{~d}$ band due to the change in the hybridization of the metal $3 \mathrm{~d}$ and metalloid sp electrons. 


\section{References}

[1] Lundquist, N., Myers, H. P. and Westrn, R., Phil: Mag. 7 (1962) 1187 ;

Cadeville, M. C. and Meyer, A. J. P., C. R. Hebd. Séan. Acad. Sci. 255 (1962) 3391.

[2] Kuentzler, R., Phys. Stat. Sol. 41 (1970) 291 ; J. Appl. Phys. 41 (1970) 908 ;

Hanson, B. D., Mahning, M. and Toth, L. E., Z. Naturforsch. 26a (1971) 739 .

[3] Kuentzler, R., J. Low Temp. Phys. 7 (1972) 309.

[4] Herr, A., Kuentzler, R. and Meyer, A. J. P., J. Appl. Phys. 40 (1969) 1375.

[5] Pickart, S. J. and Nathans, R., Phys. Rev. 123 (1961) 1163 ;
Moss, J. and Brown, P. J., J. Phys. F : Metal Phys. 2 (1972) 358

[6] Ron, M. and Mathalone, Z., Phys. Rev. B 4 (1971) 774.

[7] Bernas, H. and Campbell, I. A., Phys. Lett. 24A (1967) 74.

[8] Vincze, I. and Campbell, I. A., J. Phys. F : Metal Phys. 3 (1973) 647.

[9] Pearson, W. B., Handbook of Lattice Spacing and Structure of Metals (Pergamon Press, Oxford) 1967.

[10] Cadeville, M. C., Thesis, Strasbourg-France (1965).

[11] JesSer, R., HerR, A. and SChwaller, R., to be published in the Proceedings of the International Conference of Magnetism ICM-73. 